\title{
Quality Improvement in XY Process at ABC Corporation
}

\author{
Ryan Jeffrey P. Curbano, Maritess D. Manlongat, Arlene D. Castor Engr. Ma. Elena De Chavez, \\ Janwill Cyril G. Caiga, Evangeline P. Consigo, Jasmin V. Malibiran
}

\begin{abstract}
ABC Corporation is a Taiwanese company that manufactures metal, other related products, and industry in need of thin sheet metal fabrication. The main objective of the study is to improve the M450G1010Z08 that occurred in press brake section, which is the primary problem of the company. The researchers used the Six Sigma Methodology as a technique of reducing quality issues. The research design used in the study is applied research. Based on the result of the study, the researchers found out through stratification process that the main problem was the wrong dimension of M450G1010Z08. In the measure phase, the researchers measured the wrong dimension defects using binomial process capability, which resulted in processing $Z$ value of 1.08, indicating the process is not capable. In the analyze phase, researchers found out that the root cause of the problem is the open size of mould that exceeds $0.20 \mathrm{~mm}$ in the front side. In the improve phase, the procedure for modification of mould was done to meet the project target from $14.12 \%$ to $4 \%$. After the implementation, the researchers found out that the wrong dimension of M450G1010Z08 was reduced from $14.12 \%$ to 2.12\%. Also, the process $Z$ increased from 1.08 to 2.03 and investigated that the process performance is capable after the implementation of the improvement. The improvement was done to improve work instruction for modification of the open size of the mould.
\end{abstract}

Index Terms - Quality Improvement, Press Brake Process, DMAIC, Wrong Dimension, Mould

\section{INTRODUCTION}

$\mathrm{ABC}$ Corporation is a metal stamping sub-contractor for the leading EMS and OEM manufacturers in the world. It specializes in manufacturing metal component parts for Electronics and Telecommunications, Automotive Industry, Home Appliances, Computer Hardware and Networks, Power Supplies, Bank Notes and Bending Machines and other related products and/or industry in need for thin sheet metal fabrication and/or assemblies.

Likewise, ABC Corporation has the most comprehensive production layout and firmly backed up by a one-stop shop solution from our research and development, tooling design \& tooling fabrication, precision stamping, turret punching, press brake bending, laser cutting, argon \& spot welding, CNC tapping, plating \& painting finishing, silkscreen printing, metal parts assembly, quality assurance, \& after

Revised Manuscript Received on April 12, 2019. Philippines

Dr. Maritess D. Manlongat, Westmead International School, Philippines

Dr. Arlene D. Castor Westmead International School, Philippines

Engr. Ma. Elena De Chavez, Westmead International School, Philippines

Janwill Cyril G. Caiga, Westmead International School, Philippines Evangeline P. Consigo, Westmead International School, Philippines

Jasmin V. Malibiran, Westmead International School, Philippines
Dr. Ryan Jeffrey P. Curbano, Westmead International School,

sales services. But sometimes their products undergo a series of processes which affect its quality.

Based on the data collected that the main defect is the wrong dimension. However, the wrong dimension is the open-size of sheet metal based on the design of the customer. This could be acquired in the different work centers such as stamping, press brake, spot weld, tapping, argon, Subcon, laser, deburring, and shearing. It was identified that the most contributor to the wrong dimension is the press brake process based on the data collected.

Therefore, press brake is a critical process and used in the bending of sheet metal. Press-brake bending is a sheet metal forming process where the sheet is subjected to a bending load and can perform different operations such as $\mathrm{V}$ bending, U-drawing, and L-bending. To do so, a bottom tool is mounted on a lower, stationary beam and a top tool is mounted on a moving upper beam. The sheet metal is placed between the two tools, and the top tool is pressed down [1].

On the other hand, the factors in contributing the wrong dimension such as by the operators, in setting up the program, wrong material used, no $3 \mathrm{D}$, tolerances in the work instruction, mould used and for the v-die used.

Also, this study identifies the root causes of the wrong dimension, which affect the quality of the product, and also it will contribute to reducing the wrong dimension. Moreover, this study will benefit the company in performing the process easily and efficiently, increasing their productivity, and gaining customer satisfaction. Six Sigma methodology was used to reduce the wrong dimension of M450G1010Z08.

Six Sigma aimed to improve quality by minimizing and eliminating errors, defects, and variations. The highly competitive business ensures the good quality products and services which help to maintain customers' satisfaction and loyalty and lessen the risk and cost of the faulty goods [2].

The main purpose of this study is to improve the quality of M450G1010Z08 wrong dimension defect occurred in the press brake section with the use of Six Sigma - DMAIC methodology.

\section{Objectives of the Study}

The primary purpose of this research was to improve the quality of M450G1010Z08 wrong dimension defect in press brake process. Specifically, this research aimed to answer the following questions (1) to define the current condition of $\mathrm{ABC}$ Corporation (2) to measure the capability analysis and percentage defects of M450G1010Z08 in press brake section 
(3) to analyze the root cause of wrong dimension of M450G1010Z08 (4) to improve the wrong dimension of M450G1010Z08 in the press brake section by adjusting the mould (5) to develop of control plan based on the proposed method.

\section{METHODOLOGY}

This research utilized an applied research type to find out the possible effective solutions on the problems that the company encountered. The applied research design is a scientific method which involves the use of historical data of $\mathrm{ABC}$ Corporation, which function as the main tool for solving and improving the current problem of the company.

\section{RESULTS AND DISCUSSION}

Definition of Current Defect Condition at ABC Corporation

\section{Table 1. Defect Data of ABC Corporation}

\begin{tabular}{lccccc}
\hline \multicolumn{1}{c}{ DEFECTS } & $\begin{array}{c}\text { QUANTITY } \\
\text { REJECTED }\end{array}$ & $\begin{array}{c}\text { QUANTITY } \\
\text { INSPECTED }\end{array}$ & $\begin{array}{c}\text { Defect } \\
\%\end{array}$ & $\begin{array}{c}\text { Relative } \\
\text { Frequency } \\
(\%)\end{array}$ & $\begin{array}{c}\text { Cumulative } \\
\text { Frequency } \\
(\%)\end{array}$ \\
\hline Wrong Dimension & $3,091.00$ & $90,237.00$ & 3.43 & 13.76 & 13.76 \\
Material Defect & 299.00 & $12,829.00$ & 2.33 & 9.36 & 23.13 \\
Reversed Bending & 210.00 & $12,539.00$ & 1.67 & 6.73 & 29.86 \\
Wrong Spot & 12.00 & 721.00 & 1.66 & 6.69 & 36.54 \\
Scratches & 197.00 & $12,131.00$ & 1.63 & 6.56 & 43.10 \\
Bend Mark & 2.00 & 127.00 & 1.57 & 6.33 & 49.43 \\
Rusty & 273.00 & $20,938.00$ & 1.30 & 5.24 & 54.67 \\
Loose Thread & 5.00 & 448.00 & 1.11 & 4.48 & 59.15 \\
Moving Pin & 12.00 & $1,124.00$ & 1.07 & 4.29 & 63.44 \\
Over Press & 7.00 & 682.00 & 1.03 & 4.12 & 67.57 \\
Wrong Bending & 1.00 & 100.00 & 1.00 & 4.02 & 71.59 \\
Deform & 106.00 & $11,926.00$ & 0.89 & 3.57 & 75.16 \\
Chip Mark & 279.00 & $31,532.00$ & 0.88 & 3.56 & 78.71 \\
Tool Mark & 70.00 & $8,003.00$ & 0.87 & 3.51 & 82.23 \\
Mould Test & 90.00 & $10,444.00$ & 0.86 & 3.46 & 85.69 \\
Wrong Cut & 31.00 & $3,814.00$ & 0.81 & 3.27 & 88.95 \\
Punch Mark & 108.00 & $13,569.00$ & 0.80 & 3.20 & 92.15 \\
Offset & 20.00 & $2,779.00$ & 0.72 & 2.89 & 95.04 \\
Dent Mark & 25.00 & $3,886.00$ & 0.64 & 2.58 & 97.63 \\
Wrong Feed & 46.00 & $\mathbf{7 , 7 9 0 . 0 0}$ & 0.59 & 2.37 & 100 \\
\hline TOTAL & & & $\mathbf{2 4 . 8 9}$ & & \\
\hline
\end{tabular}

Based on the gathered data, the following are a different kind of defects in ABC Corporation. The data computed by dividing quantity rejected over quantity inspected multiplied by 100 to get the defect percentage. Also, computed the relative frequency and cumulative frequency was arranged in descending order.

The total defect percentage was calculated with a value of $24.89 \%$. A Pareto chart was created to identify the main problem. Pareto chart as an effective tool to analyze the specific problem need to prioritize and help to reveal the vital few contributors and that account for most quality problems [3]. In line with this, the stratification process was used to determine the main focus of the problem.

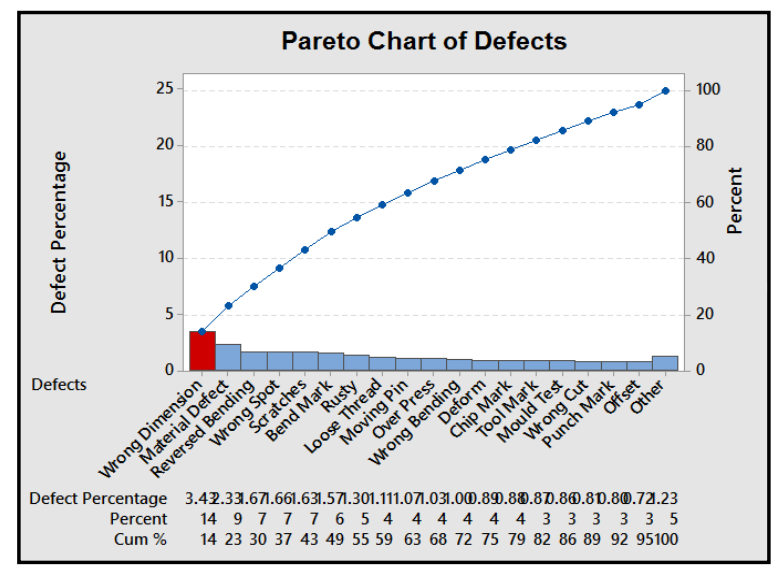

Figure 1. Pareto Chart of Defects

Figure 1 illustrates the Pareto chart of defects that needs to prioritize. Based on the figure, $20 \%$ of the problem or the useful many were tool mark, mould test, wrong cut, punch mark, offset, dent mark and wrong feed are the whiles $80 \%$ of the problem or the vital few were wrong dimension, material defect, reversed bending, wrong spot scratches, bend mark, rusty, loose thread, moving pin, over press, wrong bending, deform and chip mark.

Therefore, it was the first stratification process by identifying all defects in ABC Corporation.

Table 2. Defect Data for Section Line with Wrong Dimension Defect

\begin{tabular}{lcccc}
\hline SECTION LINE & MAY & JUNE & JULY & AVERAGE \% \\
\hline Press Brake & 2.52 & 1.45 & 1.88 & 1.95 \\
Deburring & 1.17 & 1.69 & 1.89 & 1.58 \\
Welding & 1.57 & 1.73 & 0.38 & 1.23 \\
Tapping & 0.59 & 1.02 & 1.07 & 0.89 \\
Stamping & 0.56 & 0.82 & 1.40 & 0.92 \\
Spotweld & 0.85 & 1.24 & 1.26 & 1.12 \\
Painting & 1.36 & 1.20 & 0.67 & 1.08 \\
NCT & 0.67 & 0.71 & 1.35 & 0.91 \\
Laser & 0.56 & 0.72 & 1.45 & 0.91 \\
\hline
\end{tabular}

Table 2 shows the defect data for section line with wrong dimension defects. This was the second stratification process. It resulted that the most contributor to the wrong dimension in terms of section line is the press brake process having 1.95 defect percentage.

\section{Table 3. Defect Data of Part Code with} Wrong dimension Defect 


\begin{tabular}{|c|c|c|c|}
\hline PARTCODE & $\begin{array}{l}\text { QUANTITY } \\
\text { REJECTED }\end{array}$ & $\begin{array}{l}\text { QUANTITY } \\
\text { INSPECTED }\end{array}$ & $\begin{array}{c}\text { DEFECT } \\
\text { PERCENTAGE }(\%)\end{array}$ \\
\hline 2P024899-001 & 10 & 200 & 5.00 \\
\hline 4P048122-001 & 1 & 100 & 1.00 \\
\hline 4P048124-001 & 7 & 299 & 2.34 \\
\hline CG42E070-1 & 1 & 12 & 8.33 \\
\hline DC260010-1 & 1 & 15 & 6.67 \\
\hline FS70A111BZ0B & 3 & 142 & 2.11 \\
\hline FS70A111DZ05 & 1 & 42 & 2.38 \\
\hline FS70B111AZ08 & 1 & 50 & 2.00 \\
\hline FS70B111BZ06 & 2 & 67 & 2.99 \\
\hline FS70S1120Z00 & 1 & 46 & 2.17 \\
\hline FS70T1161Z09 & 1 & 54 & 1.85 \\
\hline FS70T122AZ02 & 1 & 87 & 1.15 \\
\hline FS70T1281Z05 & 2 & 100 & 2.00 \\
\hline H14010-MX1504 & 1 & 30 & 3.33 \\
\hline J3R0J501AZ06 & 2 & 152 & 1.32 \\
\hline M450G1010Z08 & 180 & 1275 & 14.12 \\
\hline J3R0J507PZ02 & 1 & 97 & 1.03 \\
\hline J3R0J601AZ05 & 1 & 173 & 0.58 \\
\hline RPMON403PZ03 & 2 & 150 & 1.33 \\
\hline RPMOL112PZ02 & 2 & 60 & 3.33 \\
\hline RPMOJ517PZ03 & 1 & 100 & 1.00 \\
\hline RPMOJ301BZ06 & 2 & 105 & 1.90 \\
\hline RPMOJ102PB02 & 2 & 100 & 2.00 \\
\hline RPMOJ102PB02 & 2 & 104 & 1.92 \\
\hline LB33G6160Z03 & 7 & 99 & 7.07 \\
\hline LB33JN33PZ00 & 5 & 60 & 8.33 \\
\hline LB33U2560Z02 & 9 & 100 & 9.00 \\
\hline M450A2020Z08 & 8 & 124 & 6.45 \\
\hline NQBOF512PZ02 & 50 & 450 & 11.11 \\
\hline NQBOG1380Z01 & 54 & 1002 & 5.39 \\
\hline PE1P018386-001 & 11 & 116 & 9.48 \\
\hline PE2P025958-001 & 28 & 260 & 10.77 \\
\hline
\end{tabular}

Table 3 shows the defect data of every product/part code that contains the wrong dimension defects occurred in the press brake section. It was shown that the M450G1010Z08 has the highest defect percentage having $14.12 \%$. With quantity rejected of 180 items and quantity inspected of 1,275 items.

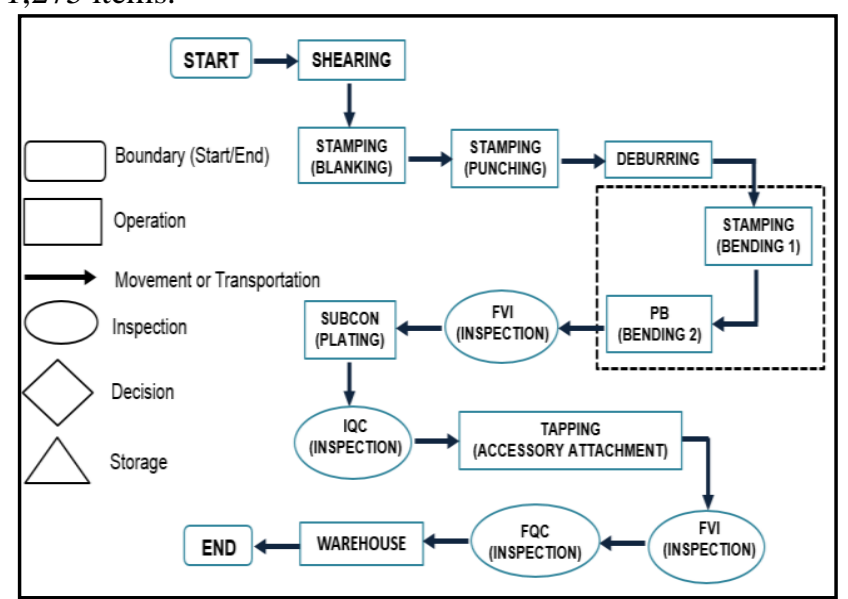

Figure 2. Process Mapping of M450G1010Z08

Figure 2 shows the process map of M450G1010Z08 illustrated in the different shape with the designated meaning, and the rounded rectangle is for boundary (start/end), square for operation, oblong for inspection, an arrow for movement or transportation, diamond for decision and also triangle for storage. The point of mapping these steps is to make them visual, making the connections and feedback loop obvious, with the aim of improving the overall process [4].

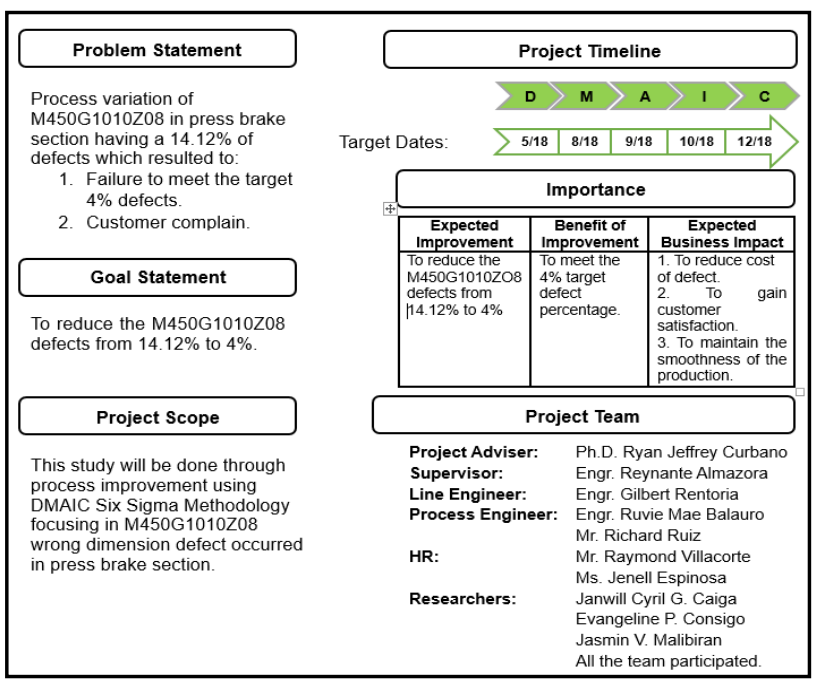

Figure 3. Project Charter

Figure 3 shows the detailed project charter of the study. The problem statement was processed variation of M450G1010Z08 in press brake process using DMAIC methodology for quality improvement to reduce defect percentage from $14.12 \%$ to $4 \%$. In addition, it stated the target improvement, importance of the study, and the project team, including the adviser, the representative from the company as well as the researchers'. Project Charter as an effective tool in setting out exactly what the project will achieve [5].

Measurement of Capability Analysis and Percentage of Defect of M450G1010Z08 in Press Brake Process

Table 4. Time Series for M450G1010Z08 Wrong Dimension Defect

\begin{tabular}{ccccc}
\hline DATE & $\begin{array}{c}\text { QUANTITY } \\
\text { REJECT }\end{array}$ & $\begin{array}{c}\text { QUANTITY } \\
\text { INSPECTED }\end{array}$ & $\begin{array}{c}\text { M450G1010Z08 } \\
\text { PERCENTAGE }\end{array}$ & $\begin{array}{c}\text { TARGET } \\
\text { PERCENTAGE (\% }\end{array}$ \\
\hline 2-May-18 & 11.0 & 35.0 & 31.43 & $4.0 \%$ \\
7-May-18 & 2.0 & 53.0 & 3.77 & $4.0 \%$ \\
10-May-18 & 1.0 & 20.0 & 5.00 & $4.0 \%$ \\
15-May-18 & 9.0 & 56.0 & 16.07 & $4.0 \%$ \\
19-May-18 & 13.0 & 89.0 & 14.61 & $4.0 \%$ \\
25-May-18 & 29.0 & 75.0 & 38.67 & $4.0 \%$ \\
1-Jun-18 & 4.0 & 80.0 & 5.00 & $4.0 \%$ \\
4-Jun-18 & 5.0 & 43.0 & 20.93 & $4.0 \%$ \\
7-Jun-18 & 5.0 & 35.0 & 14.29 & $4.0 \%$ \\
11-Jun-18 & 15.0 & 95.0 & 15.79 & $4.0 \%$ \\
15-Jun-18 & 12.0 & 120.0 & 10.00 & $4.0 \%$ \\
18-Jun-18 & 5.0 & 65.0 & 7.69 & $4.0 \%$ \\
23-Jun-18 & 28.0 & 105.0 & 26.67 & $4.0 \%$ \\
27-Jun-18 & 3.0 & 15.0 & 20.00 & $4.0 \%$ \\
5-Jul-18 & 14.0 & 91.0 & 15.38 & $4.0 \%$ \\
12-Jul-18 & 1.0 & 10.0 & 10.00 & $4.0 \%$ \\
17-Jul-18 & 10.0 & 109.0 & 9.17 & $4.0 \%$ \\
20-Jul-18 & 2.0 & 60.0 & 3.33 & $4.0 \%$ \\
25-Jul-18 & 1.0 & 30.0 & 3.33 & $4.0 \%$ \\
31-Jul-18 & 10.0 & 89.0 & 11.24 & $4.0 \%$ \\
\hline AVERAGE & & \multicolumn{4}{|c}{} \\
\hline
\end{tabular}

Table 4 shows the data of M450G1010Z08 wrong dimension gathered from May-July, 2018. Based on the data collected, the average percentage of M450G1010Z08 wrong dimension was $14.12 \%$ of the actual production. The target defect standard of the company was $4 \%$. The data is based on the weekly run of M450G1010Z08 in the production. 


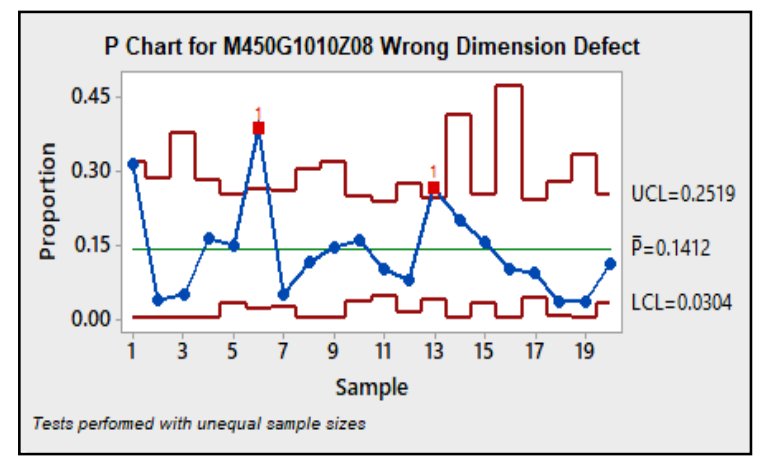

Figure 4. P Chart for M450G1010Z08 Wrong Dimension Defects

Figure 4 shows the $\mathrm{P}$ chart of M450G1010Z08 wrong dimension defect. It resulted that there are two outliers presented on 25-May-18 having 0.3867 defects and 23-Jun18 having 0.2667 defects which exceed the upper control limit. $\mathrm{P}$ chart as a tool used to verify that the process is in a state of control [6].

\section{Table 5. Binomial Process Capability Report for M450G1010Z08}

\begin{tabular}{lc}
\hline \multicolumn{2}{c}{ SUMMARY RESULTS } \\
\hline \%Defective: & 14.12 \\
Lower Cl: & 12.25 \\
Upper Cl: & 16.15 \\
Target: & 4.00 \\
PPM Def: & 141,176 \\
Lower Cl: & 122,516 \\
Upper Cl: & 161,508 \\
Process Z: & 1.08 \\
Lower Cl: & 0.99 \\
Upper Cl: & 1.16 \\
\hline
\end{tabular}

Table 5 shows the summary result of the actual binomial process capability for M450G1010Z08. In this Summary Results table, the target $(4 \%)$ indicated as the maximum allowable \%defective for the process. The \%defective resulted in $14.12 \%$, which exceed the maximum allowable $\%$ defective. However, the upper CI for \%defective was $16.15 \%$, which exceeds the maximum allowable value. Therefore, it cannot be $95 \%$ confident that the process is capable of. In addition, the process $\mathrm{Z}$ was 1.08 , which is not capable.

Root Cause Variation in Making M450G1010Z08 in Press Brake Section

Table 6. Why-why Analysis

\begin{tabular}{|c|c|c|c|c|c|c|c|}
\hline Problem & $1^{\text {st }}$ Why? & $2^{\text {tot Why? }}$ & $3^{\text {rd }}$ Why? & $4^{4^{\text {th }}}$ Why? & $5^{\text {th }}$ Why? & Control & Action \\
\hline $\begin{array}{c}\text { Wrong } \\
\text { dimension } \\
\text { variation. }\end{array}$ & $\begin{array}{c}\text { Wrong } \\
\text { Dimension } \\
\text { defect most } \\
\text { occurred in } \\
\text { M450G1010 } \\
\text { Z08. }\end{array}$ & $\begin{array}{l}\text { Due to } \\
\text { the first } \\
\text { bending } \\
\text { occurred } \\
\text { in } \\
\text { stamping } \\
\text { process. }\end{array}$ & $\begin{array}{l}\text { The first } \\
\text { bending of } \\
\text { M450G1010Z } \\
08 \text { reach the } \\
\text { maximum } \\
\text { tolerance } \\
\text { required. }\end{array}$ & $\begin{array}{l}\text { Due to the } \\
\text { mould used in } \\
\text { first bending } \\
\text { exceed the } \\
\text { maximum } \\
\text { tolerance of the } \\
\text { product. }\end{array}$ & $\begin{array}{l}\text { The open } \\
\text { size of } \\
\text { mould } \\
\text { exceeds } \\
0.20 \mathrm{~mm} \text {. }\end{array}$ & Measurable & $\begin{array}{c}\text { Fabrication } \\
\text { of mould } \\
\text { decreasing } \\
0.20 \mathrm{~mm} \\
\text { that used } \\
\text { in first } \\
\text { bending. }\end{array}$ \\
\hline
\end{tabular}

Table 6 shows the why-why analysis that consists of five why questions related to the process of M450G1010Z08.
Why-why analysis as a simple and effective tool for solving problems. Its primary goal is to find the exact reason that causes a given problem by asking a sequence of "Why" questions. Also, it helped the team focus on finding the root cause of the study and eliminate the problem and prevent the process from recurring failures [7].

The main problem was the wrong dimension variation in M450G1010Z08. The second why answered that the wrong dimension presented due to first bending in the stamping process. The third why responded that first bending reaches the maximum tolerance required — the fourth why answered that it was due to the mould use. And, the last question why responded that open size of mould exceeded $0.20 \mathrm{~mm}$ in the front side.

Modification of mould by decreasing $0.20 \mathrm{~mm}$ in the front side was the corrective action of the researchers. This table only shows the step-by-step procedure of answering the question to determine the specific cause of the problem and the possible action can be done.

Improvement Plan to Reduce the M450G1010Z08 Wrong Dimension Defects

Table 7. Work Instruction for Modification of Mould

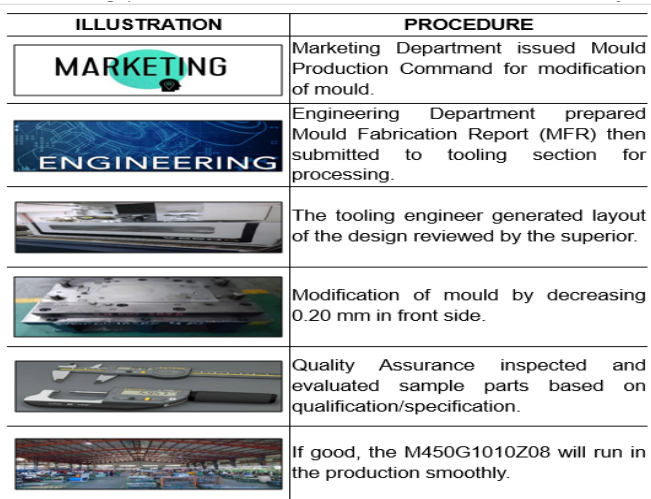

Table 7 shows the step-by-step procedure for modification of mould in M40G1010Z08. The first step was in the Marketing department issued Mould Production Command, and the second was Engineering prepared the Mould Fabrication Report, then submitted to the tooling section. The tooling engineer fabricated the mould after reviewed by the superior.

However, the mould modified by decreasing $0.20 \mathrm{~mm}$ on the front side. Then, take a sample into production for inspection and evaluation based on specification. If good the M450G1010Z08 will run in the production smoothly. 
Table 8. Time Series for M450G1010Z08 Wrong Dimension Defect After Improvement

\begin{tabular}{|c|c|c|c|c|}
\hline $\begin{array}{c}\text { Improvement } \\
\text { Time Series }\end{array}$ & $\begin{array}{l}\text { QUANTITY } \\
\text { REJECTED }\end{array}$ & $\begin{array}{l}\text { QUANTITY } \\
\text { INSPECTED }\end{array}$ & $\begin{array}{c}\text { DEFECT } \\
\text { PERCENTAGE } \\
(\%)\end{array}$ & $\begin{array}{c}\text { TARGET } \\
\text { PERCENTAGE } \\
\%\end{array}$ \\
\hline $23-$ Oct-18 & 1.0 & 100.0 & $\begin{array}{l}T .00 \\
1.00\end{array}$ & \\
\hline 24-Oct-18 & 1.0 & 48.0 & 2.08 & 4 \\
\hline $26-$ Oct- 18 & 2.0 & 69.0 & 2.90 & 4 \\
\hline $29-$-Oct- 18 & 3.0 & 100.0 & 3.00 & 4 \\
\hline 31 -Oct-18 & 1.0 & 55.0 & 1.82 & 4 \\
\hline 7-Nov-18 & 1.0 & 100.0 & 1.00 & 4 \\
\hline 8-Nov-18 & 3.0 & 80.0 & 3.75 & 4 \\
\hline 9-Nov-18 & 2.0 & 200.0 & 1.00 & 4 \\
\hline $12-\mathrm{Nov}-18$ & 1.0 & 70.0 & 1.43 & 4 \\
\hline $13-\mathrm{Nov}-18$ & 3.0 & 250.0 & 1.20 & 4 \\
\hline $22-$ Nov-18 & 1.0 & 50.0 & 2.00 & 4 \\
\hline $23-$ Nov-18 & 3.0 & 135.0 & 2.22 & 4 \\
\hline $24-N o v-18$ & 3.0 & 89.0 & 3.37 & 4 \\
\hline $26-$ Nov- 18 & 4.0 & 125.0 & 3.20 & 4 \\
\hline $29-$ Nov-18 & 2.0 & $\begin{array}{l}68.0 \\
68.0\end{array}$ & 2.94 & 4 \\
\hline 1-Dec-18 & 5.0 & 182.0 & 2.75 & 4 \\
\hline 6-Dec-18 & 1.0 & 45.0 & 2.22 & 4 \\
\hline 10-Dec-18 & 60 & 170.0 & 3.53 & 4 \\
\hline 12-Dec-18 & 20 & 1000 & 200 & 4 \\
\hline 14-Dec-18 & 5.0 & 135.0 & 3.70 & 4 \\
\hline AVERAGE & & & 2.36 & \\
\hline
\end{tabular}

Table 8 shows the improvement data of M450G1010Z08 wrong dimension gathered from October - December 2018. Based on the data collected, the average percentage was 2.36 after the improvement done by the researchers. The data is based on the weekly run of M450G1010Z08 in the production.

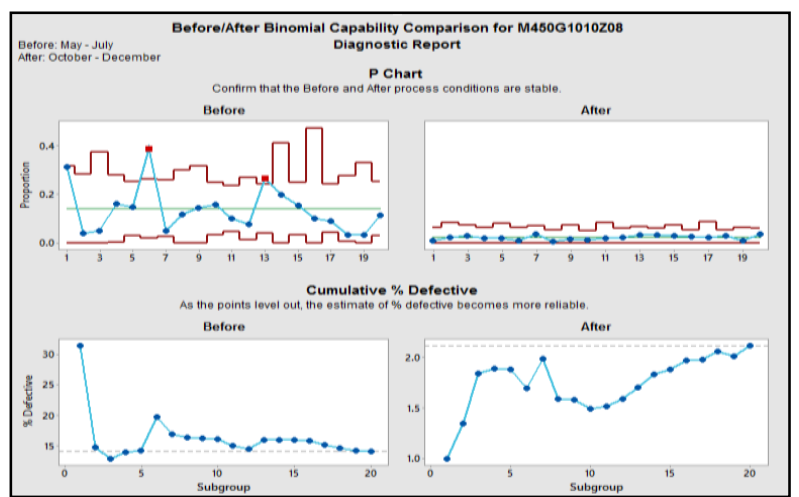

Figure 5. Before/After Binomial Capability Comparison for M450G1010Z08 Diagnostic Report

Figure 5 shows the diagnostic report for a comparison of the binomial capability of M450G1010Z08 before and after the improvement. This was constructed to determine the gap of the improvement visually.

Based on the figure, before improvement, the result was there an outlier while after an improvement, all points are stable. Also, presented the cumulative \%defective, before improvement it stabilized mean \%defective line while after an improvement most points level out on the \%defective line.

Table 9. Before/After Binomial Capability Comparison for M450G1010Z08 Summary Report

\begin{tabular}{ccccc}
\hline & & Before & After & Change \\
\hline & \%Defective & 14.12 & 2.12 & -12 \\
PROCESS & $95 \%$ Cl & $(12.25,16.15)$ & $(1.56,2.82)$ & \\
CAPABILITY & PPM (DPMO) & 141,176 & 21,188 & -119988 \\
(Overall) & Process Z & 1.08 & 2.03 & 0.95 \\
& Number of subgroups & 20 & 20 & \\
PROCESS & Average subgroup size & 63.75 & 108.55 & \\
CHARACTERI- & Total items tested & 1275 & 2171 & \\
ZATION & Number of defectives & 180 & 46 & \\
& & & & \\
\hline
\end{tabular}

Table 9 shows the summary report for the binomial capability of M450G1010Z08 before and after the improvement. Based on the summary, the percentage of defective items was reduced by $85 \%$ from $14.12 \%$ to $2.12 \%$. Process characterization indicated that 20 subgroups before and after improvement. Before improvement resulted that 180 items rejected over 1,275 items inspected while after improvement was 46 items rejected over 2,171 items inspected.

In addition, before improvement, the process \%defective was not significantly less than the maximum acceptable level ( $p>0.05$ ) while after the improvement, the process \%defective is significantly less than the maximum acceptable level $(\mathrm{p}<0.05)$. Also, the process $\mathrm{Z}$ was improved from 1.08 to 2.03 which presented that the process performance is capable

Table 10. Significance of Improvement

\begin{tabular}{c|c|c|c|c}
\hline Paired T-Test & DEFECT \% & T-VALUE & P-VALUE & INTERPRETATION \\
\hline Before & 14.12 & 0.0532 & 0.000 & Significant \\
After & 2.12 & & & \\
\hline \multicolumn{2}{l}{ Legend: If the P-Value $>0.05$, not significant, If the $P$-Value $<0.05$, significant. }
\end{tabular}

Table 10 shows the Hypothesis test before and after the improvement. Paired T-Test is a statistical technique used in 'before-after' studies, or when the samples are the matched pairs, or when it is a case-control study. Hypothesis Testing using Paired T-Test was used to test if there a significant difference between the actual and the improvement [8].

The equivalent of $\mathrm{T}$-value was 5.32, and the $\mathrm{P}$-value is 0.000. Since the P-value equal to 0 and less than 0.05 , the null hypothesis (Ho) is rejected. Thus the alternative hypothesis (Ha) is accepted. Therefore, there is a significant difference between before and after improvement. Also, the value of the mean had a difference equivalent to 1.93 .

To Control the Improvement Plan Done Through Implementation at $A B C$ Corporation

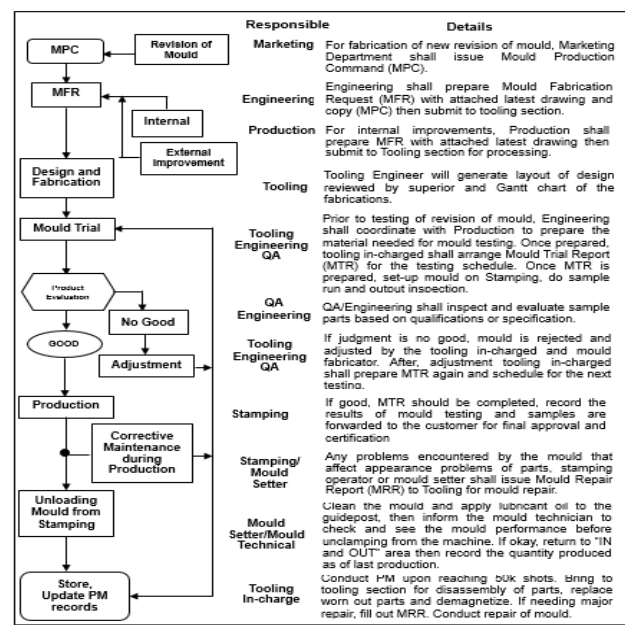

Figure 8 shows the process flow for the control plan. The process begins at the Marketing Department by issuing issue Mould Production Command (MPC). Engineering Department Engineering will prepare Mould Fabrication Request (MFR) with attached latest drawing and copy (MPC) then submit to the tooling section. 
Prior to testing of modified mould, Engineering will coordinate with production to prepare the material needed for mould testing. Once prepared, tooling in-charged will arrange Mould Trial Report (MTR) for the testing schedule. Once MTR is prepared, set-up mould on stamping, do sample run and output inspection.

Followed by QA/Engineering will inspect and evaluate sample parts based on qualifications or specification. If the judgment is no good, mould is rejected and adjusted by the tooling in-charged and mould fabricator. After, adjustment tooling in-charged will prepare MTR again and schedule for the next testing. While if good, MTR should be completed, record the results of mould testing and samples are forwarded to the customer for final approval and certification.

Once approved by the customer, tooling encoder will communicate with the stamping section to use the newly approved mould for production use.

After all, clean the mould and apply lubricant oil to the guidepost, then inform the mould technician to check and see the mould performance before unclamping from the machine. If okay, return to "IN and OUT" area then record the quantity produced as of the last production.

\section{CONCLUSION}

Based on the findings of the study, the following were the conclusion:

In the define phase, concluded that the wrong dimension has the highest percentage attributed by M450G1010Z08 having a percentage of 14.12. In the measure phase, used binomial capability analysis concluded that the process is not capable with the process $\mathrm{Z}$ value of 1.08 and was found two outliers using $\mathrm{P}$ chart. In the analyze phase, found out that the root cause of the wrong dimension is the open size of mould that exceeds $0.20 \mathrm{~mm}$ in the front side. In the improve phase, the developed procedure for modification of mould which resulted to a decrease in defect percentage from $14.12 \%$ to $2.12 \%$ and improved process $\mathrm{Z}$ from 1.08 to 2.03 and found significant after improvement. And, in the control phase, developed process flow of control plan to sustain the improvement done.

\section{RECOMMENDATION}

Based on the findings and conclusion of the study, the researchers recommended to the future researchers to conduct a further study regarding the wrong dimension defect to determine the potential and special causes of the problem and develop another effective improvement regarding the problem. It also suggested that the second problem identified in the Pareto chart should be chosen if they are planning to take conduct research and make sure that the project has a focus and one goal. And it suggested to other companies to apply Six Sigma Methodology as a tool in reducing the defects, increasing profit, producing highquality products, and gain customer satisfaction.

\section{REFERENCES}

1. Shah, Y., 2013 Applications of Different Types of Press Brakes - Mechanical and Hydraulic Press Brake
2. Raghunath, A. \& Dr. Jayathirtha, R. (2013). "Barriers for Implementation of Six Sigma by Small and Medium Enterprises." Vol: 2 No. 2

3. Mancinelli, F. (2015). "The Art and Science of Analyzing Software Data." Retrieved from https://www.sciencedirect.com

4. Deming, (2010). "A simple approach to improvement by making a process visible."

5. Harrin, E. (2010). "Role and a Purpose of a Project Charter"

6. Wiesenfelder, H. (2015). "The P Chart for Quality Control: A Specialized Control Chart for Six Sigma Projects with Attribute Data"

7. Toyoda (2012). Lean Management. "5 Whys: The Ultimate Root Cause Analysis Tools

8. Shier, R. 2012 Advancement through Clarity http://www.statisticssolutions.com 